Boer, M.E. de, Depla, M., Woijtkwiak, J., Visser, M.C., Widdershoven, G., Francke, A., Hertogh, C.M.P.M. Life-and-death decision-making in the acute phase after a severe stroke: interviews with relatives. Palliative Medicine: 2015, 29(5), 451-457

\begin{tabular}{|l|l|}
\hline $\begin{array}{l}\text { Postprint } \\
\text { Version }\end{array}$ & 1.0 \\
\hline Journal website & http://pmi.sagepub.com/content/early/2015/01/23/0269216314563427.full.pdf \\
\hline Pubmed link & $\underline{\text { http://www.ncbi.nlm.nih.gov/pubmed/25634632 }}$ \\
\hline DOI & $10.1177 / 0269216314563427$ \\
\hline
\end{tabular}

This is a NIVEL certified Post Print, more info at http://www.nivel.eu

\title{
Life-and-death decision-making in the acute phase after a severe stroke: Interviews with relatives
}

\author{
MARIKE E DE BOER ${ }^{1}$ MARJA DEPLA ${ }^{1}$ JOANNA WOJTKOWIAK $^{2}$ MARIEKE C VISSER $^{3}$ GUY AM \\ WIDDERSHOVEN $^{4}$ ANNEKE L FRANCKE $^{5,6}$ CEES MPM HERTOGH $^{1}$ \\ ${ }^{1}$ Department of General Practice and Elderly Care Medicine, EMGO Institute for Health and \\ Care Research, VU University Medical Center, Amsterdam, The Netherlands \\ ${ }^{2}$ Department of Care and Wellbeing, University of Humanistic Studies, Amsterdam, The \\ Netherlands \\ ${ }^{3}$ Department of Neurology, VU University Medical Center, Amsterdam, The Netherlands \\ ${ }^{4}$ Department of Medical Humanities, EMGO Institute for Health and Care Research, VU \\ University Medical Center, Amsterdam, The Netherlands \\ ${ }^{5}$ NIVEL - Netherlands Institute for Health Services Research, Utrecht, The Netherlands \\ ${ }^{6}$ Department of Public and Occupational Health, EMGO Institute for Health and Care \\ Research, VU University Medical Center, Amsterdam, The Netherlands
}

\begin{abstract}
Background: Decision-making in the acute phase after a severe stroke is complex and may involve life-and-death decisions. Apart from the medical condition and prognosis, quality of life and the deliberation of palliative care should be part of the decision-making process. Relatives play an important role by informing physicians about the patient's values and preferences. However, little is known about how the patients' relatives experience the decision-making process.
\end{abstract}

Aim: To elicit the perspective of relatives of severe stroke patients with regard to the decision-making process in the acute phase in order to understand how they participate in treatment decisions.

Design: An exploratory qualitative interview approach guided by the principles of grounded theory.

Settings/participants: Relatives of severe stroke patients $(n=15)$ were interviewed about their experiences in the decision-making process in the acute phase.

Results: Four categories reflecting relatives' experiences were identified: (1) making decisions under time pressure, (2) the feeling of 'who am I' to decide, (3) reluctance in saying 'let her die' and (4) coping with unexpected changes. Following the treatment proposal of the physician was found to be the prevailing tendency of relatives in the decision-making process. 
Boer, M.E. de, Depla, M., Woijtkwiak, J., Visser, M.C., Widdershoven, G., Francke, A., Hertogh, C.M.P.M. Life-and-death decision-making in the acute phase after a severe stroke: interviews with relatives. Palliative Medicine: 2015, 29(5), 451-457

Conclusion: A better understanding of the latent world of experiences of relatives that influence the decision-making process may help physicians and other health-care providers to better involve relatives in decision-making and enhance the care, including palliative care, for patients with severe stroke in line with their values and preferences. Communication between physician and relatives seems vital in this process.

\section{What is already known about the topic?}

- Decision-making in the acute phase after stroke is complex and may involve life-and-death decisions.

- The integration of palliative care early in the care trajectory of patients with severe stroke may improve the quality of decision-making for severe stroke patients and their families, but the evidence-base is limited.

- While it is known that relatives of severe stroke patients play an important role in informing physicians about the patient's values and preferences, little is known about the experiences of these relatives in the decision-making process.

\section{What this paper adds?}

- The latent world of experiences described in this paper entails difficulties in the tendency of relatives to follow the treatment proposal of the physician and shows how these experiences may influence the delivery of care in line with the patients' values and preferences.

- The prevailing tendency of relatives in making treatment decisions is to follow the proposal(s) of the physician.

- Relatives are reluctant in expressing their wish to forgo (further) treatment; even if they are convinced, this is in line with the wish of the patient.

\section{Implication for practice, theory or policy?}

- A better understanding of the latent world of experiences of relatives that influence the decision-making process will help physicians and other healthcare providers to better involve relatives in decision-making and enhance the care for patients with severe stroke in line with the patients' values and preferences.

- Physicians need to become increasingly aware of the importance of their role in the decision-making process and invest in enhancement of the physicianrelative communication, with a focus on the patient's values and preferences and the dilemmas faced by relatives.

- Continuous attention to clear communication of the uncertainty of prognosis, attention for the dying process and open discussion of the possibilities of palliative care should be provided. 
Boer, M.E. de, Depla, M., Woijtkwiak, J., Visser, M.C., Widdershoven, G., Francke, A., Hertogh, C.M.P.M. Life-and-death decision-making in the acute phase after a severe stroke: interviews with relatives. Palliative Medicine: 2015, 29(5), 451-457

\section{INTRODUCTION}

Stroke is a common and potentially life-threatening condition. Life-and-death decisions in the acute phase after a severe stroke are therefore common in the care for stroke patients. The dilemma often faced is whether to treat, which may keep the patient alive but may leave him dependent on intensive care-giving, or to stop or refrain from treatment which may result in death, but may also deprive patients to possibly recover and adapt to the new situation. In situations where prognosis is certain and no doubts exist about the outcome and the patient's preferences, a decision to withdraw or withhold life-sustaining treatment may be relatively straightforward. Although prediction models exist and physicians can make a prognostic estimate based on their previous experiences, all of these methods are surrounded with uncertainty, limitations and potential for bias. ${ }^{1}$ Therefore, treatment decisions under these circumstances are often complex and involve trade-offs. ${ }^{2}$ What adds to this complexity is the fact that in the case of a severe stroke, the patient is often unable to express his own preferences. An example of complex decisionmaking exists when deciding for or against thrombolysis - the immediate treatment for acute ischaemic stroke. The benefit of improved survival must be weighed with the risk of possible severe functional disability. This decision is often the first of many such decisions, which might include mechanical ventilation, artificial nutrition and hydration, but also the treatment of future complications such as infections, and the implementation of rehabilitation. Such decisions are inevitably individualized and value based.

Although the evidence-base is limited, the integration of palliative care early in the care trajectory of patients with severe stroke may improve the quality of decisionmaking for severe stroke patients and their families. ${ }^{1,3}$ Palliative care may enhance complex decisions to be guided by a more ethical approach. ${ }^{4}$ It includes, for example, patient- and family-centred care, the development of goals of care and having eye for palliative treatments and options at the end of life. ${ }^{1}$ Palliative care needs of severe stroke patients are found to be high, ${ }^{1,5}$ but the deliberation of palliative care in the acute phase after stroke may be hampered, as the 'prevailing culture underpinning stroke care reflects a growing evidence-base for acute neurological intervention, patient activation and rehabilitation approaches'. ${ }^{3}$

In the scope of shared decision-making, the patients' values and wishes have to be taken into account in the decision-making process, despite the fact that physicians are ultimately responsible for the treatment decisions made. As most severe stroke patients are unable to communicate in the acute phase, often their relatives are faced with the challenging role of expressing preferences, based on what they think the patient would have wanted and what constitutes an acceptable outcome for that person.

The role of relatives in decision-making has been criticized as their capacities may be blunted and potentially leading to decisions that do not accurately reflect patient's values. ${ }^{6,7}$ Making decisions for others may also lead to negative emotional effects on relatives, like burdensome feelings. ${ }^{8,9}$ However, despite their crucial role in the decision-making process, ${ }^{3,10}$ the experiences of relatives with making care and 
Boer, M.E. de, Depla, M., Woijtkwiak, J., Visser, M.C., Widdershoven, G., Francke, A., Hertogh, C.M.P.M. Life-and-death decision-making in the acute phase after a severe stroke: interviews with relatives. Palliative Medicine: 2015, 29(5), 451-457

treatment decisions in the specific setting of the acute phase after a severe stroke are hardly explored.

Our objective was to elaborate on the perspective of relatives as key participants in the decision-making process in the acute phase after severe stroke and to understand the way they are involved in treatment decisions in these potentially life-threatening situations. Insight into the experiences of relatives may contribute to a better understanding of the challenges in decision-making after a severe stroke, which may enable physicians, nurses and other health-care personnel to better attune their guidance in the decision-making process to the individual experiences and dilemmas of relatives.

\section{METHOD}

\section{Design, participants and setting}

An exploratory qualitative approach guided by the principles of grounded theory was used. ${ }^{11}$ In-depth semi-structured interviews were conducted between December 2011 and March 2013 with relatives of patients who had suffered from a severe stroke. A lack of existing studies in this area made us focus on exploring experiences as a first step. Purposive sampling ${ }^{12}$ was used as we strived to include information-rich cases and to maximize variety in experiences. Therefore, maximum variety was sought with regard to the relation between participant and patient and the outcome of the stroke in terms of death or survival. To further maximize variation, participants were recruited from three academic and one non-academic hospital; a nursing home through contacts with neurologists, a physician assistant, a nursing specialist and a researcher; and through additional contacts with a general practitioner and an elderly care physician. Both recruiters and relatives received written information about the background of our research. To be eligible for inclusion, three criteria were used: (1) the patient has had a 'severe' stroke; (2) the stroke occurred between 2 and 6 months prior to the interview and (3) the relative interviewed had actively participated in the medical decision-making process for a stroke patient in the acute phase. The severity of the stroke was judged by the professionals, and a severe stroke was defined as an acute, serious and life-threatening stroke, with often uncertainty of the prognosis and discussions about complex treatment decisions. Relatives were excluded if they did not have sufficient command of the Dutch language to be able to conduct an adequate interview. Consent to participate in the study was obtained from all participants, first by telephone and in writing at the day of the interview. Participation was voluntary, relatives could withdraw at any time and anonymizing data protected confidentiality. None of the approached relatives declined participation or had to be excluded. Enrolment of participants was continued until data saturation ${ }^{13}$ was reached after 15 interviews. Demographic data of the interviewees and patients are provided in Table 1 . The study was approved by the Medical Ethics Committee of the VU University Medical Center. 
Boer, M.E. de, Depla, M., Woijtkwiak, J., Visser, M.C., Widdershoven, G., Francke, A., Hertogh, C.M.P.M. Life-and-death decision-making in the acute phase after a severe stroke: interviews with relatives. Palliative Medicine: 2015, 29(5), 451-457

\section{[TABLE 1.]}

\section{Interviews}

An initial interview guide was developed by all members of the project team with backgrounds in neurology, elderly care medicine, psychology, nursing and ethics, helped by input from informative interviews with professionals dealing with stroke patients in actual practice. The interviews involved a face-to-face conversation with participants, with an explorative character, and guided with open-end questions about different aspects of the decision-making process in the acute phase after stroke. They were conducted retrospectively as it enhances the abilities of participants to reflect upon their experiences and put them into words. All but one of the interviews took place in the participant's home (one interview took place in a designated room within the hospital upon the specific request of the participant). Two, independently working, authors of this article (M.E.dB. and J.W.) performed all the interviews; both had interview experience and no relationships existed between them and the participants or patients. Although working independently, interview experiences were shared to diminish differences in approaching the participants. A short introduction prior to the interview was used to explain the research goals, to answer any questions and to make participants feel at ease. Initial questions were designed to elicit the participant's general experiences with the care provided in the acute phase (i.e. What do you recall about the period shortly after diagnosis? Can you describe your feelings at that time?). Subsequent questions focussed on the decision-making process, including type of decisions, information provision, perceived roles and communication with health-care staff. The interview guide was refined as data collection progressed to further explore emerging themes. Participants were given ample space to tell their own personal experiences. The interviews varied in length from 23 to $119 \mathrm{~min}$ (average: $57 \mathrm{~min}$ ). All interviews were digitally recorded and transcribed verbatim by an external professional agency.

\section{Analysis}

The transcripts were subjected to qualitative analysis, by using the constant comparative technique, ${ }^{11}$ and facilitated by the software of ATLAS.ti. Analysis incorporated an iterative process of reading and re-reading the transcripts in order to identify emergent themes or categories. Initial line-by-line coding was performed to attach open codes to all issues that seemed relevant in the decision-making process, such as 'wish patient', 'wish relative', 'discussion with physician', 'physical state patient' or 'prognosis'. This process was done for the first few interviews separately by two researchers (M.E.dB. and M.D.), after which the codes were discussed until consensus was reached. Thereafter, both researchers (M.E.dB. and M.D.) were involved in the focussed coding process of the interviews, whereby the initial codes were refined, compared and grouped into tentative categories like 'time', 'wishes', 'communication' or 'advise of physician'. These categories were discussed with all 7 members of the research group until consensus was reached. Subsequently, and helped by memos, analysis became progressively analytic resulting in codes being raised to major categories, which were again discussed with the broader research group, and are presented in this article. 
Boer, M.E. de, Depla, M., Woijtkwiak, J., Visser, M.C., Widdershoven, G., Francke, A., Hertogh, C.M.P.M. Life-and-death decision-making in the acute phase after a severe stroke: interviews with relatives. Palliative Medicine: 2015, 29(5), 451-457

\section{RESULTS}

Relatives of patients who had suffered from an acute severe stroke had to make various decisions in the acute phase after stroke, including the decision to forgo treatment. Four, not mutually exclusive, categories reflecting relatives' experiences were identified: (1) making 'choices' under time pressure, (2) the feeling of 'who am I' to decide, (3) reluctance in saying 'let him die' and (4) coping with unexpected changes. Despite differences in experiences, following the treatment proposal of the physician was found to be the prevailing tendency of relatives in the decision-making process.

\section{Making 'choices' under time pressure}

Facing their loved one suffering from a severe stroke was hard for relatives. The acute phase after stroke was overwhelming, and they felt treatment decisions had to be taken under a time pressure. Under these circumstances, some relatives acted in a reflex, where choices did not seem to feel as actual choices. For example, one woman explained how she had agreed with the physicians' proposal to start treatment, to only realize during the interview that her husband might not have wanted this treatment: If I had realised [he might have come out this severely handicapped], and this was explained to me clearly, I would have said 'no' to this treatment. (Participant 14)

This relative explained how, because of the limited time to reflect, her thinking had been dominated by feelings of emotional attachment and 'not willing to give up hope', which had caused her to have a preference for treatment decisions primarily focussed on survival.

Another relative was told by the physician that he 'should not have any hopes of him [the patient; his son] coming out of this okay. And if he did come out of it, he would be fully handicapped'. This relative explained how this caused him to agree with the suggestion of the physician to forgo treatment: I did not have another option. (Participant 9)

In this case, the decision may seem relatively straightforward, but it was taken under time pressure. As a result, relatives may lack time to adapt which prevents them from being emotionally prepared to go along with such difficult treatment decisions. This is illustrated by this relative who described how it had made him feel as a 'technical' choice at the time and had left him struggling with the 'emotional part' afterwards: It is underestimated what people go through. (Participant 9)

\section{Feeling of 'who am I' to decide}

Relatives were found to have difficulties with participating in treatment decisions for the patient. This feeling was described by one of the relatives as 'who am I' to decide. 
Boer, M.E. de, Depla, M., Woijtkwiak, J., Visser, M.C., Widdershoven, G., Francke, A., Hertogh, C.M.P.M. Life-and-death decision-making in the acute phase after a severe stroke: interviews with relatives. Palliative Medicine: 2015, 29(5), 451-457

One of the relatives explained how she would rather leave the treatment decisions to the physician and felt relieved to arrive in the hospital: Now we are in good hands. Now I do not have to decide by myself anymore. (Participant 13)

The physician, in this case, suggested this relative to consult a friend or other family member to support her in agreeing (or disagreeing) with his treatment proposal.

In another case, it seemed relatively straightforward for the family members to decide to not resuscitate the patient in case of heart failure, as she was in coma and short of breath after three strokes. Even though the patients' sister felt that she would not want this condition for her sister, she found herself struggling to answer the physicians question 'do you want her to be resuscitated?': Can I decide this ..., do I have to decide this? (Participant 8)

\section{Reluctance in saying 'let her die'}

There were also relatives who went along with the treatment initiated by the physician, despite their feelings of reluctance. In these cases, the family favoured a decision to forgo (further) treatment, based on the (reconstructed) wish of the patient, but was reluctant in expressing this wish: As if I want her to die. (Participant 2)

For example, in one case, the patient was expected to 'not make it through the night'. The relative involved felt the patient should be spared from further suffering. However, as he was unsure about his reaction, he refrained from discussing this with the physician: I don’t want to say: 'I want my sister-in-law to die now'.(Participant 1)

Upon the question what would have happened if the option to forgo further treatment had been brought up, he answered unambiguously, 'I would have said "yes" immediately'.

\section{Coping with unexpected changes}

Relatives were found to also experience difficulties in coping with unexpected changes in the medical situation or prognosis of the patient. This can be illustrated by a family member who, after unexpected improvement in the situation of the patient, told the other family members: This goes wrong, because she recovers. (Participant 2)

For this particular relative, the situation was even more complex as she had been reluctant in expressing this was not what the patient would have wanted (see previous category), causing the health-care personnel to react in the opposite way by expressing ‘joy’ to see (minor) improvements.

A clear prognosis, or at least awareness of its uncertainty, was found to be crucial for making decisions in line with the values and preferences of the patient. This can be illustrated by the case of a relative who decided to withdraw artificial nutrition and hydration from his mother as she was 'given up'. This decision turned into a 'moral 
Boer, M.E. de, Depla, M., Woijtkwiak, J., Visser, M.C., Widdershoven, G., Francke, A., Hertogh, C.M.P.M. Life-and-death decision-making in the acute phase after a severe stroke: interviews with relatives. Palliative Medicine: 2015, 29(5), 451-457

dilemma' as his mother 'miraculously recovered a little' and started asking for fluids. It was only then that this relative realized that he had initially made a life-and-death decision. This knowledge left him with the unpleasant feeling of having 'played God' (Participant 5).

\section{DISCUSSION}

In this exploratory qualitative study, we investigated the experiences of relatives in the decision-making process after severe strokes.

Taking decisions 'under pressure' may be partially inherent to the context of decision-making in the acute phase after a severe stroke. At the same time, it points out to the importance of time in this decision-making process. Overwhelmed by the situation, relatives' initial responses may be inclined by emotional attachment and feelings of 'I don't want to give up hope'. This means their own emotional preferences dominate the decision-making process in the acute phase after stroke, causing them to possibly bias the preferences of the patient.

Patients with progressive life-limiting illnesses are thought to shift their goals of care, starting with life-prolongation as overriding goal, via maintaining function to eventually comfort as the sole goal of care. ${ }^{14}$ However, in severe stroke, this process of possible goal shifting is under pressure. The suddenness of the illness makes that there is not enough time to adapt, to overthink and to revise decisions. In addition, it often involves relatives who need to prioritize the care goals on behalf of the patient and to decide what the patient would have wanted. These relatives are also deprived of time to grieve, to adapt and to carefully weigh the treatment options provided. Relatives may benefit from a physician being aware of the (time) pressure felt and helping them prioritize the goals of care in line with the values of the patient.

Our data also show how relatives can struggle with the role of decision-maker imposed upon them. For example, relatives responding with 'Who am I to decide?' may experience difficulties in justifying their role as decision-maker, similar to relatives saying, 'I don't want to be the one saying: "let him die”'. Without sharing with the physician what they think and feel is best for the patient, this may lead to treatment decisions not in line with the patients' values and preferences. A betterquality physician-relative communication may contribute to a higher confidence of relatives in their role in the process of decision-making ${ }^{15}$ and alleviation of their distress associated with decision-making. ${ }^{16}$ Therefore, it is important for physicians to acknowledge their influence in the decision-making process to increase awareness about their own role and be aware of the reluctance of relatives in participating in 'life-and-death' decisions. Along with insight into the experiences and dilemmas of relatives, this may assist them and other professionals to adapt their approach in terms of support and guidance accordingly. Some relatives may benefit from a physician taking up a 'facilitative role', whereby the physicians guide the relative through a process of clarifying the patients' values and applying those values to the decision. Others may be helped by a physician taking up a more 'collaborative' or even 'directive' role. ${ }^{17}$ However, being directive may risk relatives experiencing the decision-making process as a 'technical' rather than an 'emotional' process, reflected 
Boer, M.E. de, Depla, M., Woijtkwiak, J., Visser, M.C., Widdershoven, G., Francke, A., Hertogh, C.M.P.M. Life-and-death decision-making in the acute phase after a severe stroke: interviews with relatives. Palliative Medicine: 2015, 29(5), 451-457

in the response 'I have no other option', which potentially leaves relatives struggling with the emotional part afterwards.

Although predicting outcome in the acute phase after severe stroke is known to be difficult, ${ }^{18}$ discussing the uncertainty of prognosis proved to be an important part of this discussion. Without this knowledge, we found, for example, relatives to not realize they were making a life-and-death decision. In this respect, our findings confirm other research concluding that still 'too often prognosis is mistakenly taken to be the act of telling what will be, rather than what may be or is likely to be'. ${ }^{19}$ Open discussion about the prognosis and its uncertainties along with the possibility to revise decisions and to forgo further treatment under certain circumstances seemed limited.

Our findings suggest that in the context under study, palliative care seems limited to the transition from active treatment to forgoing treatment and was only applicable to circumstances where prognosis was clearly unfavourable and/or no doubts existed about the unacceptability of the outcome.

The much broader possibilities of a palliative care approach, such as treatment of pain and other, physical, psychosocial and spiritual problems, ${ }^{20}$ do not seem to be the main focus in decision-making in the acute phase after severe strokes. Relatives can benefit from physicians creating space for discussion about palliative care and forgoing treatment, especially as we found relatives reluctant in expressing preferences to forgo further treatment.

A limitation of this study lies in the recruitment process being retrospective, as retrieving patients with severe strokes from hospital systems proved to be hard. Selection bias in this process cannot be excluded, but is largely compensated by maximizing variation in settings and the background of our recruiters and the analysis process of looking for variety in findings until saturation was reached. Furthermore, our study was conducted in the Netherlands. This makes it important to take into account differences in care organization and, for example, attitudes towards end-of-life issues when considering transferability of our findings to other settings or countries.

This article confirms other research in that decision-making for others is challenging. ${ }^{2,6}$ In line with Berger et al., ${ }^{21}$ we conclude that 'making decisions for a relative is far more complex, dynamic and nuanced than is generally understood'. Especially in severe stroke, the decision-making process is influenced by multiple uncertainties and biases in, for example, prognosis, outcome and interpreting patient preferences. $^{2,22}$ Our study adds to this general knowledge, by providing insight into the perspective of relatives with the decision-making process in the specific setting of the acute phase after severe strokes. It reveals a latent world of experiences that influence the decision-making process, which contribute to the tendency of relatives to follow the treatment proposal of the physician.

We conclude that enhancement of communication between physicians and relatives in the acute phase after severe strokes will provide opportunities to better involve 
Boer, M.E. de, Depla, M., Woijtkwiak, J., Visser, M.C., Widdershoven, G., Francke, A., Hertogh, C.M.P.M. Life-and-death decision-making in the acute phase after a severe stroke: interviews with relatives. Palliative Medicine: 2015, 29(5), 451-457

relatives in the decision-making process. Relatives may benefit from physician nivel supporting them in discussing their experiences, feelings and dilemmas, in addition to being clear about the uncertainty of the prognosis and providing guidance in prioritizing goals of care in line with the values of the patient. A better understanding of the experiences of the relatives will enable physicians to adapt their support and guidance accordingly and hereby enhance the care for severe stroke patients in line with their preferences and values.

\section{ACKNOWLEDGMENTS}

We would like to thank all participants and everyone who have helped us in the recruitment phase of the study.

\section{REFERENCES}

1. Holloway RG, Arnold RM, Creutzfeldt CJ, et al.; on behalf of the American Heart Association Stroke Council, Council on Cardiovascular and Stroke Nursing and Council on Clinical Cardiology. Palliative and end-of-life care in stroke: a statement for healthcare professionals from the American Heart Association/American Stroke Association. Stroke 2014; 45: 1887-1916.

2. Creutzfeldt CJ, Holloway RG. Treatment decisions after severe stroke: uncertainty and biases. Stroke 2012; 43: 3405-3408.

3. Burton CR, Payne S. Integrating palliative care within acute stroke care services: developing a programme theory of patient and family needs, preferences and staff perspectives. BMC Palliat Care 2012; 11: 22.

4. Crozier S, Santoli F, Outin H, Aegerter P, Ducrocq X, Bollaert PÉ. Severe stroke: prognosis, intensive care admission and withhold and withdrawal treatment decisions. Rev Neurol (Paris). 2011; 167(6-7): 468-73.

5. Burton CR, Payne S, Addington-Hall J, et al. The palliative care needs of acute stroke patients: a prospective study of hospital admissions. Age Ageing 2010; 39: 554-559.

6. Vig EK, Startks H, Taylor JS, et al. Surviving surrogate decision-making: what helps and hampers the experiences of making medical decisions for others. J Gen Intern Med 2007; 22(9): 1274-1279.

7. Schenker $\mathrm{Y}$, Crowley-Matoka M, Dohan D, et al. I don't want to be the one saying 'we should just let him die': intrapersonal tensions experienced by surrogate decision makers in the ICU. J Gen Intern Med 2012; 27(12): 1657-1665.

8. Wendler D. Systematic review: the effect on surrogates of making treatment decisions for others. Ann Intern Med 2011; 154(5): 336-346.

9. Braun UK, Naik AD, Mc Cullough LB. Reconceptualizing the experience of surrogate decision making: reports vs genuine decisions. Ann Fam Med 2009; 7(3): 249-253.

10. Payne S, Burton C, Addington-Hall J, et al. End-of-life issues in acute stroke care: a qualitative study of the experiences and preferences of patients and families. Palliat Med 2010; 24(2): 146-153.

11. Charmaz K. Constructing grounded theory. A practical guide through qualitative analysis. London: Sage, 2006.

12. Patton MQ. Qualitative evaluation and research methods. 2nd ed. Newbury Park, CA: SAGE, 1990.

13. Guest G, Bunce A, Johnson L. How many interviews are enough? An experiment with data saturation and variability. Field Methods 2006; 18: 59-82.

14. Gillick MR. Rethinking the central dogma of palliative care. J Palliat Med 2005; 8(5): 909-913.

15. Majesko A, Hong SY, Weissfeld L, et al. Identifying family members who may struggle in the role of surrogate decision maker. Crit Care Med 2012; 40(8): 2281-2286. 
Boer, M.E. de, Depla, M., Woijtkwiak, J., Visser, M.C., Widdershoven, G., Francke, A., Hertogh, C.M.P.M. Life-and-death decision-making in the acute phase after a severe stroke: interviews with relatives. Palliative Medicine: 2015, 29(5), 451-457

16. Torke AM, Petronio S, Sachs GA, et al. A conceptual model of the role of communication in surrogate decision making for hospitalized adults. Patient Educ Couns 2012; 87(1): 54-61.

17. White DB, Malvar G, Karr J, et al. Expanding the paradigm of the physician's role in surrogate decision-making: an empirically derived framework. Crit Care Med 2010; 38(3): 743-750.

18. Teale EA, Forster A, Munyombwe T, et al. A systematic review of case-mix adjustment models for stroke. Clin Rehabil 2012; 26(9): 771-786.

19. Hemphill JC 3rd., White DB. Clinical nihilism in neuroemergencies. Emerg Med Clin North Am 2009; 27(1): 27-37.

20. World Health Organization. WHO definition of palliative care, http://www.who.int.proxy.library.uu.nl/cancer/palliative/definition/en (2014, accessed 18 April 2014).

21. Berger JT, DeRenzo EG, Schwartz J. Surrogate decision making: reconciling ethical theory and clinical practice. Ann Intern Med 2008; 149(1): 48-53.

22. Holloway RG, Benesch CG, Burgin WS, et al. Prognosis and decision making in severe stroke. JAMA 2005; 294(6):

725-733.

\section{TABLE}

Table I. Demographics of interviewees and patients.

\begin{tabular}{|c|c|c|c|c|c|c|c|}
\hline \multirow[t]{2}{*}{ No. } & \multicolumn{3}{|c|}{ Interviewee } & \multicolumn{4}{|c|}{ Patient } \\
\hline & Age & Gender & $\begin{array}{l}\text { Relation to } \\
\text { patient }\end{array}$ & Age & Gender & $\begin{array}{l}\text { Relation to } \\
\text { interviewee }\end{array}$ & Additional information \\
\hline I & $\sim 75$ & Male & Brother-in-law & 75 & Female & Sister-in-law & Deceased after 2 weeks \\
\hline 2 & 69 & Female & Niece & 90 & Female & Aunt & Deceased after 2 weeks + I day \\
\hline 3 & 47 & Female & Niece & 70 & Female & Aunt & Deceased after 5 days \\
\hline 4 & 77 & Male & Husband & 73 & Female & Wife & Transferred to nursing home \\
\hline 5 & 66 & Male & Son & 94 & Female & Mother & Deceased after I week \\
\hline 6 & 47 & Female & Daughter & 74 & Female & Mother & $\begin{array}{l}\text { Deceased after about } 2 \text { months in } \\
\text { nursing home }\end{array}$ \\
\hline 7 & 81 & Male & Husband & 80 & Female & Wife & $\begin{array}{l}\text { Deceased after } 5 \text { weeks ( } 2 \text { weeks in } \\
\text { hospital; } 3 \text { weeks in nursing home }\end{array}$ \\
\hline 8 & 65 & Female & Sister & 68 & Female & Sister & $\begin{array}{l}\text { Deceased about } \mathrm{I}-2 \text { weeks after } \\
\text { third stroke }\end{array}$ \\
\hline 9 & $?$ & Male & Father & 50 & Male & Son & Deceased \\
\hline 10 & 65 & Female & Niece & 79 & Female & Aunt & Deceased after 9 days \\
\hline II & 51 & Female & Daughter & 80 & Female & Mother & Back to living independently \\
\hline 12 & 79 & Male & Husband & 79 & Female & Wife & $\begin{array}{l}\text { Back home with partner (refused } \\
\text { to be admitted to the hospital) }\end{array}$ \\
\hline 13 & 56 & Female & Wife & 57 & Male & Husband & Back home \\
\hline 14 & 64 & Female & Wife & 79 & Male & Husband & Deceased \\
\hline 15 & $\sim 50$ & Male & Son & 83 & Female & Mother & Admitted to nursing home \\
\hline
\end{tabular}

